\title{
Variación del pronombre personal en las tres ediciones del Libro del Cauallero Zifar ${ }^{1}$
}

\section{Personal pronoun variation in the three editions of Libro del Cauallero Zifar}

\author{
Daniel Jiménez-Sánchez \\ Universidad de Sevilla, Sevilla \\ danijisan@hotmail.com
}

ACCESO ABIERTO / OPEN ACCESS

Cita: Jiménez-Sánchez, Daniel (2021). Variación del pronombre personal en las tres ediciones del Libro del Cauallero Zifar. Textos en Proceso, 7(2), pp. 68-82.

https://doi.org/10.17710/tep.2021.7. 2.5jimenez-sanchez

Editoras: Esperanza Alcaide Lara (Universidad de Sevilla) y Ana Pano Alamán (Università di Bologna)

Recibido: 12/09/2021

Aceptado: 05/12/2021

Conflicto de intereses: El autor ha declarado que no posee conflicto de intereses.

Copyright: @ Daniel Jiménez-Sánchez. Esta obra está bajo licencia Creative Commons Reconocimiento 4.0.

\section{Resumen}

Es bien sabido que el pronombre ha presentado una evolución considerable desde el latín hasta nuestros días. Los cambios producidos en la época bajomedieval fueron de especial importancia para constituir lo que sería siglos más tarde el sistema pronominal del español moderno. Este trabajo abarcará, concretamente, el estudio del pronombre personal en época bajomedieval, tomando como objeto de estudio las tres primeras ediciones de una obra de reconocida importancia para la literatura española medieval, las cuales suponen todo un recorrido cronológico por la historia de la lengua en la Baja Edad Media: el Libro del Cauallero Zifar.

Palabras clave: cambio lingüístico, pronombre, Cauallero Zifar, variedades textuales, morfosintaxis histórica del español.

\begin{abstract}
It is well known that the pronoun has been subject to a deep evolution since Latin was spoken. More specifically, changes which took place during the Late Medieval period were especially important regarding the pronominal system of modern,
\end{abstract}

\footnotetext{
${ }^{1}$ Este trabajo se basa en el TFG (Trabajo de Fin de Grado) realizado para el Grado en Filología Hispánica de la Universidad de Sevilla, defendido el 11 de julio de 2021 con calificación de "Matrícula de honor" con el título "Análisis de las secuencias de diálogo en las tres ediciones del Libro del Cauallero Zifar", que se ha llevado a cabo con la ayuda de la Beca de Iniciación a la investigación de la Universidad de Sevilla, bajo la dirección de la profesora Marta Fernández Alcaide, dentro del proyecto del Ministerio de Ciencia, Innovación y Universidades "Tradicionalidad discursiva e idiomática, sintaxis del discurso, traducción y cambio lingüístico en la historia del español moderno: prosa (pre-)periodística/ensayística y literaria”, del grupo de investigación El español hablado en Andalucia (HUM-134).
} 
sixteenth-century Spanish. This article concerns the personal pronoun in the Late Medieval Ages, focusing on the first three editions of Libro del Cauallero Zifar. These are prominent in Spanish medieval literature since they cover the history of late-medieval Spanish language as a whole.

Keywords: linguistic change, pronoun, Cauallero Zifar, textual varieties, historic Spanish morphosyntax.

\section{Objetivos y metodología}

El principal objetivo de este proyecto es el de dar visibilidad a una obra de indudable relevancia en el campo de la historia de la lengua española, como es Libro del Cauallero Zifar (en adelante, Zifar), estudiándolo desde el punto de vista de las diferencias en el plano pronominal personal entre sus tres primeras ediciones, pretendiendo también con ello hacer hincapié en cuestiones del análisis del discurso histórico y de la oralidad en la escritura. Para ello, se ha llevado a cabo un estudio teórico y práctico a partir de las variaciones encontradas entre las tres primeras ediciones conservadas del $\mathrm{Zifar}^{2}$, recogiendo las secuencias de variación entre estas y tomando siempre como punto de partida el códice $\mathrm{M}^{3}$.

Por otra parte, se ha tomado como referencia la metodología de otros trabajos que analizan la variación lingüística entre los testimonios de una misma tradición textual, desde los más actuales, como son el de Octavio de Toledo (2011), el de Pons Rodríguez (2006) o el de Fernández-Ordóñez (2006), hasta estudios de generaciones pasadas, como el de De Andrés Castellanos (1964). Debemos acercarnos a los textos de la forma más propicia posible, tratando de allanar al máximo la labor científica sin perder calidad en el desarrollo de las investigaciones ${ }^{4}$. También conviene recordar que este proyecto no tiene como objetivo realizar un análisis del pronombre personal en la obra; sino el de llevar a cabo un estudio de las

\footnotetext{
${ }^{2}$ Estas son el manuscrito más antiguo, fechado en el siglo XIV, conservado en la BNE (Biblioteca Nacional de España) en Madrid (códice M); la edición de París, que data de 1464, conservada en la BNF (Bibliothèque Nationale de France) (códice P); $y$, por último, la edición de Sevilla de 1512, que se conserva tanto en la BNF como en el Palacio Real de Madrid, aunque esta última es una réplica elaborada en 1529 (códice S).

${ }^{3}$ Salvo en sus tres lagunas de páginas perdidas, que representa una proporción muy pequeña del total, donde solo se ha comparado $\mathrm{P}$ frente a S.

${ }^{4}$ A pesar de que lo idóneo en este tipo de estudios es trabajar de forma directa sobre las fuentes primarias, se ha elegido establecer el número de páginas y línea acorde con la transcripción de Wagner en su estudio sobre el Zifar (1929). El motivo de esta decisión reside, fundamentalmente, en las posibilidades que ofrece este texto ya trascrito a la hora de ser digitalizado, pues así posteriormente podrá trabajarse con él a partir de herramientas informáticas (concretamente, con los comandos "set" o "grep," empleados por el sistema operativo "unix") que permiten encontrar expresiones regulares en un documento de texto plano (".txt"). Además, unificar el tipo de citas ofrece mayores facilidades a la hora de su posterior búsqueda (en el mismo estudio de Wagner ya se ofrecen las secuencias de cambio del códice $\mathrm{M}$ con respecto a los códices $\mathrm{P}$ y el $\mathrm{S}$, aportando además el número de página del manuscrito del primero de ellos). Esto no quiere decir que no se hayan cotejado los manuscritos, sino que es el texto de Wagner el que ha servido para unificar los criterios de ejemplificación del análisis. No obstante, la realización de este trabajo ha despertado la necesidad de elaborar en el futuro una nueva edición revisada de cada uno de los tres testimonios de la obra, pues para un estudio de mayor envergadura será primordial contar con una base de datos tomada directamente de los manuscritos originales.
} 
variaciones existentes entre las tres principales ediciones de la misma, tomando como punto de partida las formas pronominales personales, por su riqueza morfosintáctica y el amplio campo de posibilidades que ofrecen ${ }^{5}$. Tampoco se trata de un estudio cuantitativo, a pesar de que en ciertos momentos se aporten datos numéricos que sirvan de contraste. Este proyecto pretende realizar una aproximación a los aspectos ecdóticos del Zifar a partir del estudio de una forma lingüística concreta (en este caso, del pronombre), aunque se procurará elaborar en el futuro, con ayuda del tratamiento informático, un estudio cuantitativo y completo de las variaciones lingüísticas existentes entre las ediciones de la obra.

\section{Sobre el Libro del Caballero Zifar. Autor, fecha, estilo y estruc- tura}

Afirma Wagner (1929) que el Zifar fue escrito a lo largo del primer tercio del siglo XIV, probablemente poco después de 1303, a juzgar por el año del fallecimiento del papa Bonifacio III, mencionado en el prólogo. Según explican González (1983) y Cacho Blecua (1996), otros autores, como Moldenhauer (1931), habrían fechado la obra después del año 1321, año en el que falleció la reina doña María, pues se basarían en que se habla sobre ella en el prólogo como si ya hubiese muerto. Sin embargo, la crítica mayoritaria respalda más la teoría de Wagner, achacando los sucesos mencionados por Moldenhauer como «interpolaciones tardías hechas por los copistas» (González, 1983, p. 21).

Con respecto a la autoría del Zifar, Wagner afirma que debió ser un clérigo, aunque no hay nada probado. La gran mayoría de autores coincide en el nombre de Ferrán Martínez, arcediano de Madrid en la iglesia de Toledo hasta 1302. Hernández Martínez (1978) señala que este clérigo de Toledo fue tanto arcediano como sellador de los reyes Alfonso X y Sancho IV, afirmando también que escribió la obra sobre 1304, coincidiendo con la hipótesis de Wagner ya mencionada. Por tanto, se puede decir que es muy probable que el Zifar fuese escrito en la primera década del siglo XIV por Ferrán Martínez, aunque «no se tenga una prueba definitiva de ello» (González, 1983, p. 24).

El Libro del Caballero Zifar presenta una indiscutible relevancia en el panorama lingüístico y literario medieval, al ser considerado «uno de los más tempranos romans en prosa de la literatura castellana, escrito en el primer tercio del siglo XIV» (Cacho Blecua, 2018, p. 1). Es una obra escrita en ausencia de los preceptos y formas clásicas que tanto marcaron a los textos de la literatura medieval, por lo que es innovadora en su estructura. Bebe de diversas fuentes literarias, tanto occidentales como orientales, siendo la más destacada la del Calila e Dimna y cultiva el género didáctico-moralizante, pues, tal y como afirma González (1983, p. 23), abundan las digresiones y refranes.

$\mathrm{Su}$ estructura ha generado polémica entre los investigadores en cuanto a la división en bloques de contenido se refiere. La obra presenta una división formal en

\footnotetext{
${ }^{5}$ Por ese motivo no todo el paradigma pronominal está analizado en este proyecto, tan solo el pronombre personal, debido fundamentalmente a los límites de extensión y a que resulta el más relevante para el estudio de la variación.
} 
cuatro partes, que se pueden simplificar en dos, atendiendo a un criterio secuencial (historia de Zifar frente a historia de Roboan) o a un criterio de diferencias en el discurso (parte narrada frente a parte dialogada). Según González (1983), en ambos casos los protagonistas comparten una serie de características que los relacionan, como si de figuras paralelas se tratase. Por tanto, se puede afirmar que se trata de una obra con unidad propia.

Por último, se pueden señalar algunos aspectos de relevancia en cuanto a las características editoriales de los manuscritos se refiere, sin ánimo de extendernos excesivamente en cuestiones codicológicas, pues no es el objetivo de este trabajo. El manuscrito M (manuscrito más antiguo de la obra) es un códice anónimo escrito en papel de color crudo, que consta de 194 folios, de los que ha perdido diez: el primero del Prólogo ${ }^{6}$, cuatro folios entre las actuales páginas 176 y 177 y cuatro folios más entre 186 y 187, además del último, aunque posiblemente este careciese de anotaciones. Por otra parte, el manuscrito P presenta muchas similitudes con el original en lo que respecta al tipo de letra empleada ${ }^{7}$, al uso de abreviaturas y a la disposición en columnas. Sin embargo, la riqueza artística de su bordado, de sus ilustraciones y de su encuadernación lo convierten, en palabras de Lucía Megías (1996, p. 104), "en una joya codiciada para embellecer cualquier biblioteca". Por último, debemos decir que el manuscrito $\mathrm{S}$ realmente corresponde a dos códices diferentes (ambos con supresión del prólogo): el primero, escrito en 1512 e impreso por Jacobo Cromberger en Sevilla; y una copia del mismo elaborada en 1529, elaborada también por el mismo editor.

\section{Análisis del pronombre personal en el Libro del Caballero Zifar}

En el presente trabajo se abordará el estudio del pronombre personal, tomando como referencia ejemplificada el Zifar, obra de muy elevado interés filológico que cuenta con una gran riqueza y variedad pronominal, atendiendo a diferentes aspectos: su evolución morfológica, el orden sintáctico, el estudio de las interferencias funcionales de los clíticos y las formas de tratamiento.

\subsection{Morfología}

La variación más destacada que sufrieron los pronombres tónicos fue la incorporación (que se volvió definitiva en época bajomedieval) de una forma para la tercera persona, siendo este un hecho común a todas las lenguas romances. Durante la época medieval, el romance castellano utilizó diversos demostrativos latinos para referirse a la tercera persona del singular, aunque al final se acabó decantando por el de lejanía "ILLE > él", el que quizá expresase de manera más cercana el significado de esta persona.

Los pronombres personales de $1^{\mathrm{a}}$ y $2^{\mathrm{a}}$ persona del singular mantuvieron la forma latina "TU > tú", tan solo con variaciones de carácter fonético en " $\mathrm{E}(\mathrm{G}) \mathrm{O}>$ yo". Cabe destacar que las formas yo y tú solo se emplearon como sintagma nominal

\footnotetext{
${ }^{6}$ Pérdida ya reseñada una vez el códice llegó a la BNE en el Ýndice de los Manuscritos procedentes de la Biblioteca del Duque de Osuna (1886), Madrid.

${ }^{7}$ Destaca como diferencia principal con $\mathrm{M}$ el empleo de la grafía $\underline{\mathrm{R}}$ en posición inicial de palabra con valor de vibrante múltiple.
} 
sujeto, nunca como término de una proposición previa (a diferencia de las formas nos y vos $)^{8}$. Estos cambios se constituyeron en época muy temprana, por lo que no se encontrarán vacilaciones de este tipo en una obra cuatrocentista como es el Zifar.

Por otra parte, se produjo también la definitiva gramaticalización de las formas nosotros y vosotros, que sustituyeron a las formas tónicas nos y vos (recordemos que, para el plural en latín, las formas de nominativo y acusativo coincidían en una sola: NOS > nos; VOS $>$ vos). No obstante, no fue un cambio radical, pues en la historia de la gramática siempre debemos entender los cambios como procesos prolongados. Ya en el primer tercio del siglo XV podemos encontrar en algunos textos que empleaban discurso directo, como es el caso del Corbacho, el uso de estas nuevas formas. Según Eberenz, el uso de vosotros ya se habría generalizado algunos años antes que el de nosotros, pero lo que se puede afirmar con seguridad es que a lo largo del siglo XV esto comenzó a ser un hecho común. No debemos olvidar que el uso de las formas tónicas nos y vos como pronombres personales de $1^{\mathrm{a}}$ y $2^{\mathrm{a}}$ persona (respectivamente), no desapareció por completo hasta quizá el siglo XVI. En la misma Gramática de Nebrija (1492) se prioriza el uso de nos y vos como pronombres personales antes que las formas nosotros y vosotros, aunque Nebrija ya emplea estas últimas con frecuencia en sus explicaciones. A partir de los siglos XV y XVI, las formas tónicas nos y vos mantuvieron su uso para las fórmulas de tratamiento de cortesía, como el uso del voseo, y acompañando a la preposición con, siendo precisamente el siglo XVI el momento en el que comienzan a consolidarse en su uso (Gomila, 2018, p. 812). Sin embargo, Lapesa (2000) señala que las obras de Herrera, Ercilla y fray Luis de León mantuvieron su uso hasta ese mismo siglo, lo cual hace sospechar que posiblemente la desaparición de estas formas no fuese ni mucho menos definitiva en el XVI. Como se puede observar en el Zifar, aún se siguen empleando las formas nos y vos como pronombres tónicos de primera y segunda persona del plural, respectivamente. No se encuentran casos de empleo de las formas nosotros y vosotros, lo cual es esperable al tratarse de un texto de principios del siglo XIV. Ejemplos de ello en el texto son:

1) a. Nos vos aseguramos dixieron los caualleros $(\mathrm{M}, 73,10)$.

b. E yo ayudarvos-he a ello (M, 176, 19).

c. E amigos e parientes quierovos dezir (...) (M, 63, 5).

Sin embargo, cabe destacar que en $\mathrm{S}^{9}$ de la obra analizada, sí podemos apreciar la presencia de las formas nosotros y vosotros en el texto. Véanse los siguientes ejemplos:

\footnotetext{
${ }^{8}$ Pasando en el caso de yo, según Menéndez Pidal (1973), por un estadio intermedio *ieu, aunque autores como Malkiel (1948) ya afirmaron que su evolución fonética se produjo por disimilación vocálica

${ }^{9}$ La gramaticalización de nosotros y vosotros como sustitutos de nos y vos comienza a darse a mediados del siglo XV (Eberenz, 2004, p. 613), de ahí que exista un contraste cronológico entre los ejemplos de las ediciones M (1303) y P (1464) frente a S (1512).
} 
2) a. E nos recibremos a la vuestra muger por señora (M, 247, 18) / E nosotros rescibimos $(\ldots)(\mathrm{S}, 247,18)$.

b. E tengo que por esta razón que faria Dios mal a mi e a vos (M, 247, 3) / E tengo que por esta razón que faria Dios mal a mi e a vosotros $(\mathrm{S}, 247,3)$.

Las formas de los clíticos también se vieron afectadas por el conjunto de variaciones gramaticales que se produjo en época bajomedieval. En primer lugar, la oposición entre los grupos me $>$ me, TE $>$ te (acusativo y ablativo) y MIHI $>$ mí, TIBI $>$ ti (dativo), se hizo latente a lo largo de la Edad Media. Me y te quedaron como formas de complemento directo o indirecto, mientras que $m i$ y $t i$ solo se usaron precedidos de una preposición. La antigua oposición latina de MECUM, TECUM se representó en conmigo y contigo, (pasando previamente por *conmego y *contego) presentes en nuestra lengua actual desde las Glosas. Sus plurales, NOBISCUM, VOBISCUM, se vieron representados durante gran parte de la Edad Media por conbusco y conuusco (cuya $u$ presenta un inexplicable origen, según Cano (1988, p. 148)), pero desaparecidas en época bajomedieval, momento en el que son desplazadas por las formas actuales, con nosotros y con vosotros, posiblemente por su "mala integración pragmática" y por la tendencia a la pérdida de -co en español (García, 1991), y una vez que se asientan las formas nosotros y vosotros. Algo similar a lo que se observó anteriormente con los pronombres personales tónicos de primera y segunda persona del plural sucede al observar los ejemplos que nos proporciona el Zifar. Se vuelven a apreciar diferencias entre los testimonios de la $\mathrm{obra}^{10}$, por lo que no es de extrañar que en la primera edición se sigan empleando con frecuencia las antiguas formas conbusco y conuusco, y que, en la edición sevillana, por el contrario, nos encontremos casos de uso de las formas actuales:

3) a. Dios sera y conusco e nos dará buena gima a este fecho (M, 277, 2) / Dios sera allí con nosotros e nos dará buena gima a este fecho (S, 277, 2).

b. Querrán ellos fablar conbusco otrosy con maestría (M, 345, 11) / Querrán ellos fablar con vosotros assi mesmo con arte (S, 345, 11).

En cuanto a la forma de la tercera persona del singular, ya se dijo anteriormente que se introdujo a partir del demostrativo de lejanía latino ILLE. Por otra parte, las formas átonas proceden de, para el acusativo, ILLU(M), ILLU(D) / ILLA(M) > lo, la; y para el dativo, ILLI > le. En los casos en los que se unían el dativo y el acusativo en la misma secuencia pronominal, es decir, la evolución de las formas ILLI + illu(M), ILLU(D) / ILLA(M), se produjo una palatalización del pronombre de dativo, originándose de esta manera las formas gelo(s), gela(s). Posteriormente, en los textos cuatrocentristas (a finales del XIV, según SicotDomínguez (2002)), estas formas evolucionaron a la actual se lo(s) y se la(s) debido a un trueque de sibilantes. Sin embargo, la forma gelo perdurará en los textos hasta el primer tercio del siglo XVI, momento en el que los corpus nos indican su casi total desaparición de la lengua escrita (Girón Alconchel, 2004, p. 862). En lo que

\footnotetext{
${ }^{10}$ Recordemos que distan 148 años entre la escritura del primer manuscrito de la obra y el de Sevilla, el más tardío de los analizados en el presente trabajo
} 
respecta al Zifar, no observamos el abandono de esta forma medieval en ninguna de sus tres versiones, ni siquiera en S, lo cual va acorde con la cronología de las tres ediciones de la obra, ya que este último se escribió precisamente a principios del XVI. Algunos ejemplos de la presencia de gelo son:

4) a. E el Cauallero Zifar pesóle mucho, pero ouo gelo de otorgar (M, 47, 4).

b. Deziendo a los que encontraua que gelo tornasen (M, 86, 10).

Con respecto a las formas plurales de los clíticos de segunda persona destaca la sustitución, debido a causas meramente fónicas, de vos átono por os, gestado a finales de la época medieval (Penny, 1993, p. 163). En un principio, se trató de una reducción contextual y esporádica, producida cuando vos seguía a un verbo y este acababa en consonante. Encontramos ejemplos de ello en el texto tan solo en S, donde no solo aparece de forma esporádica, sino que comienza a haber casos de uso generalizado, mientras que tanto en $\mathrm{M}$ como en $\mathrm{P}$ se mantiene la forma original vos:

5) a. Sienpre parat mientes a los consejos que vos dieren los que vieredes que son en razón (M y P, 263, 4) / Sienpre parat mientes a los consejos que os dieren los que vieredes que son en razón $(\mathrm{S}, 263,4)$.

b. Ayna se vos oluido dixo el conde (M y P, 423, 12) / Ayna se os oluido dixo el conde (M y P, 423, 12).

No será hasta el final del siglo XV cuando esta nueva forma comenzará a usarse de manera más frecuente, siendo a partir del siglo XVI cuando acabó generalizándose. Es destacable el hecho de que no tengamos constancia de esta forma en la edición parisina, lo cual demuestra el carácter moderadamente conservador de dicha edición: a pesar de ser una copia de mediados del siglo XV, debemos tener en cuenta que se trata de una edición de una obra escrita aproximadamente un siglo atrás ${ }^{11}$. He aquí algunos ejemplos del uso de vos como clítico en el texto:

6) a. Çertas señor, yo vos lo dire dixo la reyna (M, 434, 16).

b. E dixol amigo commo vos va (M, 481, 16).

\subsection{Orden sintáctico y colocación}

No solo la morfología de los pronombres clíticos sufrió variaciones a lo largo de esta época, sino que también se vio afectada la colocación de los mismos en la oración. A pesar de que la gramática del siglo XV no representa grandes diferencias con el sistema medieval en lo que respecta al ámbito del orden de constituyentes, sí que se pueden destacar vacilaciones a lo largo de dicho siglo. Es conveniente separar entre dos situaciones a la hora de estudiar este aspecto: por un lado, la

${ }^{11}$ También se debe tener en cuenta el posible conservadurismo de la obra al tratarse de una edición rica y cuidada. Solo distan 48 años entre la escritura de $\mathrm{P}$ y $\mathrm{S}$, pero observamos que, mientras en $\mathrm{S}$ ya se dan casos generalizados del uso de $o s$, en $\mathrm{P}$ ni siquiera hay constancia de los usos esporádicos, los cuales se suponen comunes ya mediados del siglo XV. 
situación de pronombres con respecto a verbos conjugados, y por otro, con verbos en formas no personales o en su forma imperativa.

En lo que respecta a los pronombres del primer caso, cabe destacar primeramente que la norma general en el sistema medieval consistía en que ningún pronombre clítico podía encabezar una secuencia u oración, teniendo que ir este siempre ligado al verbo, o al menos, de manera pospuesta a este. Por norma general, los pronombres no podían romper una pausa, y debían apoyarse en otro elemento, pues estos no estaban aún gramaticalizados como afijo verbal. El pronombre se posponía al verbo si este iba al comienzo de la oración, o si, en su defecto, se daban algunas de estas tres situaciones: las oraciones comenzadas por $e$ o mas seguidas de verbo (7a), las comenzadas tras pausa seguidas de verbo (de la que no se encuentra registro en el Zifar) y las comenzadas por un elemento topicalizado que se antepone al verbo (7b). Así pues, podemos observarlo en el Zifar:

7) a. E dixol amigo commo vos va (M, 481, 16).

b. E el dixole que se non atreuia a lo consejar en esta razón (M, 446, 1).

Por el contrario, si la frase comenzaba por algún otro elemento (8a) o si la forma verbal era un futuro, condicional o tiempo compuesto (8b), el afijo se posponía:

8) a. E el le dixo que tíraua aquellas sangujuelas de sy" (M, 374, 7).

b. E de commo el Cauallero Amigo le fuera muy cortes, e lo que le dixiera" (M, 494, 27).

Las situaciones son variables cuando el sintagma nominal sujeto aparece explícito, pues el pronombre puede aparecer antepuesto o pospuesto, como se puede observar en los ejemplos mostrados a continuación:

9) a. E el le dixo (M, 481, 25)

b. E el dixole (S, 481, 25).

Sin embargo, lo común es encontrar el pronombre átono pospuesto al verbo, aunque también es posible que ocupe el segundo lugar en la oración. Tomando los ejemplos que Cano aporta sobre esta colocación propia y característica del sistema medieval, tenemos: "ascondense del Mio Cid" (PCid), "e dixo me otrossi" (General Estoria), "E ella dixoles" (Primera Crónica General) (1988)

Por otra parte, no se debe olvidar que los verbos de dicción ${ }^{12}$ con enclíticos responden, en la mayoría de casos, a vocativos que aparecen pronominalizados de manera anticipada. Según Leal Abad, "cuando esto ocurre, es habitual que el carácter meramente referencial del pronombre se oponga al contenido del vocativo

\footnotetext{
${ }^{12}$ Los verbos de dicción o dicendi son considerados como "verbos de lengua" por la NGRAE (2009). Otros estudios anteriores emplean la terminología de "verbos de dicción" (Serradilla, 1997), o "verbos de dicción o elocución" (Leal Abad, 2008). Se empleará la terminología de la NGRAE por ser más moderna y actualizada que el resto.
} 
posterior" (2008, p. 81). Es decir, el pronombre enclítico no funcionaría de la misma forma que el vocativo posterior, que sí presenta una función expresiva y no meramente referencial. Esto se puede observar en los siguientes ejemplos del Zifar, donde observamos cómo la función del enclítico es meramente referencial, ya que es únicamente el vocativo quien aporta expresividad. De hecho, esto se refuta al observar que la función expresiva no se ha visto mermada en $\mathrm{S}$, a pesar de la supresión del enclítico:

10) E preguntole: dueña (...) $(\mathrm{M}, 103,20)$ / E dixo: dueña $(\ldots)(\mathrm{S}, 103,20)$.

Si bien, se dan casos en los que existe una coincidencia en el carácter correferencial entre el enclítico y el vocativo. Este hecho no es común en el Zifar, apareciendo solo de manera marginal y esporádica, aunque sí lo es, por el contrario, en otras obras medievales como El libro de Apolonio (Leal Abad, 2008).

No obstante, hay constancia de otra serie de ejemplos que muestran una vacilación en la colocación de los clíticos en diferentes textos del siglo $\mathrm{XV}$, que serán, en palabras de Eberenz «precursoras de los cambios que se consumarán durante la época clásica» $\left(2004\right.$, p. 617) ${ }^{13}$. También en el Zifar encontramos excepciones:

11) Le tenian atadas las manos deziendo (...) $(\mathrm{M}, 377,11)^{14}$.

Aunque este trabajo no contempla profundizar excesivamente en este apartado, podemos afirmar que, en líneas generales, la anteposición de los clíticos se comenzó a dar en situaciones concretas, como es el caso de oraciones encabezadas por un sujeto nominal, o en la posición del pronombre con respecto a infinitivos con preposición. Posteriormente, a finales del siglo XVI y comienzos del XVII, el proceso de gramaticalización de la anteposición del pronombre átono comienza a descender paulatinamente (no obstante, hasta principios del siglo XX encontramos vestigios de esta forma, como es el caso de érase), por lo que comienza a ser común a partir de 1600 que un pronombre átono diese comienzo a una frase.

Por otra parte, en el caso de los pronombres ligados a verbos en formas no personales o en forma imperativa, la gramaticalización del pronombre en posición antepuesta al verbo conjugado de los siglos XVI y XVII trajo también consigo la gramaticalización de la posposición de los pronombres átonos en las formas no personales. Estas, dada su frecuencia de aparición sintáctica, solían llevar los enclíticos antepuestos. Encontramos alternancia de casos entre las tres ediciones analizadas:

12) a. E fuese para el cauallero, e en lugar de dezirle: Salue vos Dios! (M, 110, 16) / E fuese para el cauallero, e en lugar de le dezir: Salue vos Dios! (P y S, 110, 16).

\footnotetext{
${ }^{13}$ Dichos ejemplos, que aporta el mismo Eberenz, son: "Yo lo fize" (Corbacho), "Y elque puede sanar al que padece, no lo haciendo, le mata", (Celestina), "Las palomas se tajan como la perdiz" (Villena, Arte).

${ }^{14}$ No se observan diferencias entre ediciones en este ejemplo.
} 
b. Ca el mayordomo por le fazer onrra non quiso que veniese en pos el (M, 162, 14).

c. E quando fue a la media noche leuantaronse 10 estos dos malos ornes para yr degollar al cauallero e tomarle lo que traya $(\mathrm{M}, 124,11)$.

Dicha diferencia con los casos de pronombres unidos a verbos en indicativo y subjuntivo no presenta una causa clara, pues en latín no existía ningún tipo de diferenciación entre ambos grupos.

\subsection{Interferencias funcionales de los clíticos: laísmo, leísmo y loísmo}

Las funciones de acusativo y dativo en los pronombres de $3^{\mathrm{a}}$ persona siempre han sido vacilantes desde los orígenes de la lengua, por lo que su distinción en el discurso siempre ha sido motivo de discusión. Esta vacilación de los pronombres $l o(s)$, la(s), le(s) forma parte de los fenómenos conocidos como loísmo, laísmo y leísmo.

El origen de estos fenómenos ha sido debatido por varios historiadores de la lengua. Algunos defienden que el origen de la confusión podría radicar en la apócope del dativo: $l(e)$ o l'. Sin embargo, otros autores, como Menéndez Pidal, piensan que ya existía este fenómeno de leísmo antes del asentamiento de la apócope. Lapesa (2000) apunta que la no fijación del leísmo se debe a que la apócope del clítico no es solo apócope de le, sino que también sería apócope de lo. Así, una apócope como en los casos de viol o dixol podría ser una forma homónima para ambas posibilidades.

En palabras de Eberenz, no hay una variación conjunta ni tampoco se aprecian los límites u objetivos de esta:

La neutralización parcial de las marcas sintácticas se aprovecha para la expresión de ciertas categorías semánticas (la distinción entre entes animados y no animados, entre conceptos contables y continuos, etc.), aunque no hay unanimidad sobre su naturaleza y sobre el objetivo que perseguirían los distintos cambios (2004, p. 615).

Cabe destacar también que esta confusión no solo queda en los textos del siglo $\mathrm{XV}$, sino que se extiende también al habla de nuestros días. Es decir, parece que coexiste esta serie de vacilaciones en la función pronominal, tanto en la dimensión diacrónica, como en las hablas de hoy.

Según Lapesa (2000), el nacimiento del leísmo pudo estar ocasionado por el uso de $l e(s)$ en construcciones con objeto directo (antiguo acusativo latino) en determinadas ocasiones, por ejemplo, cuando el objeto lleva un predicativo, o cuando es sujeto de una construcción de infinitivo en subordinación, sobre todo si este coincide con el objeto de la oración subordinada. Esto contribuyó a que desde los textos del siglo XIII encontremos le(s) con función de complemento directo de muchos verbos transitivos, manteniéndose hasta el siglo XVII, tal y como afirma Fernández-Ordóñez (2001). En palabras de Cano, «dado que en casi todos los entornos mencionados el objeto implicado tenía referencia personal, ese rasgo semántico debió convertirse en decisivo para la posterior propagación del fenómeno» (1988, p. 151). Sin embargo, es importante señalar que el leísmo se produce con una intensidad considerablemente menor cuando es plural, especialmente si la variación es de les por las (aun con referencia personal). 
También se ha defendido la operancia de la distinción de género en el caso de lo (que reunía las formas ILLUM, masculino, y ILLUD, neutro). Se piensa que, con el fin de evitar tal homonimia, se pudo recurrir al uso de le como masculino, y este uso pudo extenderse para otro tipo de usos sintácticos.

Ya en los textos del siglo XV, se aprecia un notable aumento de los casos del leísmo de persona, que, según Eberenz, es mayoritario en autores como Martínez de Toledo, Teresa de Cartagena, Pulgar, San Pedro y Rojas; aunque afirma (2004, p. 616) que sigue habiendo escritores que prefieren el uso del lo etimológico. También tenemos constancia del leísmo de cosa, cuyo uso sería posteriormente motivo prestigioso en la literatura del Siglo de Oro. En el Zifar ya se aprecian algunos ejemplos de este leísmo de persona, incluso en la primera edición de la obra, como se puede observar en los siguientes ejemplos:

13) a. Bien puede ver quien le conseja bien ( $M, 13,7)$.

b. Ca yo so aquel omne que le mate por la mi desauentura (M, 30, 2).

Por último, cabe destacar que, dentro de estas vacilaciones, también se encuentran los casos de laísmo y loísmo. El laísmo corresponde al empleo de la(s) como objeto indirecto, mientras que en el loísmo se da con el empleo de $l o(s)$. Este último estaba marcado sociolingüísticamente, pues su uso quedaba adscrito al grupo de hablantes analfabetos, de escaso nivel sociocultural y de zonas rurales. Ambos fenómenos cuentan con un origen etimológico y antiguo, aunque su primer registro de aparición fuera de los casos etimológicos data del siglo XIII (en la Fazienda de Ultramar en el caso del loísmo, y en la Crónica de Juan II en el caso del laísmo). Sin embargo, no será hasta el siglo XV cuando se comienza a incrementar su frecuencia de aparición en los textos, aunque únicamente en el ámbito de Castilla, pues "no se extendió a Andalucía ni a Canarias y, por tanto, tampoco a América" (RAE, 2010, p. 1215). Antes de la época bajomedieval, por tanto, la incidencia de este fenómeno era más discreta, aunque no inexistente. Cano ha señalado que los casos de ló́smo pueden deberse a la extensión de las construcciones de doble acusativo conservadas en castellano antiguo, y que estas suelen ser más comunes en su forma plural. Recuperando los ejemplos que aporta en su obra (1988), observamos que ya desde el siglo XIII se pueden observar en la lengua escrita ciertos casos de loísmo y laísmo "Todos... davanlos vasos de oro" (Fazienda de Ultramar), "La començo a dezir..." (Historia Troyana). Pero, como se ha dicho antes, estos casos de loísmo y laísmo en los siglos XIII-XIV eran menores; su uso comienza a ser más destacable a lo largo del siglo XV, sobre todo en la lengua oral (Eberenz, 2004). En el caso del Zifar, encontramos tanto casos de laísmo (11a), ya desde la primera edición de la obra, como de loísmo, también presente en el manuscrito $\mathrm{M}^{15}(11 \mathrm{~b})$ :

14) a. E el clérigo la dixo muy bien e mucho ayna (M, 58, 8).

${ }^{15}$ Cabe destacar que no se encuentran diferencias entre ediciones en las construcciones de laísmo y loísmo. 
Es más frecuente la aparición de casos de loísmo en la obra frente a los casos de laísmo, lo cual puede ser debido al cuidado tratamiento de la oralidad que caracteriza al Zifar. No obstante, son los casos de leísmo los más frecuentes no solo en la obra, sino en la mayoría de textos de la época bajomedieval. No se aprecian cambios significativos entre los tres testimonios de la obra en lo que respecta a alteraciones de este tipo, por lo que podemos suponer que la situación de estas interferencias funcionales de los clíticos tuvo que ser similar en los siglos XIV y $\mathrm{XV}$.

\subsection{Formas de tratamiento: el voseo de cortesía}

Las formas de tratamiento son un aspecto destacable de un texto fechado en época medieval, tanto desde el punto de vista social, como desde el plano del análisis discursivo. En este apartado, nos centraremos en concreto en el uso de la forma vos y sus variantes, sobre la cual Leal Abad afirma que «la alternancia tú/vos constituye un punto fundamental en el análisis histórico de la cortesía verbal entre emisor y receptor» (2008, p. 96). Este uso alternante arranca en el latín tardío y se extiende hasta los últimos vestigios del español clásico de los Siglos de Oro (Hammermüller, 2010). El uso para el singular de las formas nos y vos (se debe recordar que el uso tras preposición responde a una función diferente) fue propio de las clases sociales más elevadas; según Cano, «nos por las altas jerarquías y vos en el tratamiento entre nobles» (Cano, 1988, p. 148). También Eberenz ha mostrado los contextos de uso de dichas formas: «Vos y la $2^{\text {a }}$ persona del plural del verbo se empleaban desde los orígenes del idioma como tratamiento de cortesía, sea de inferior a superior, sea entre interlocutores de estatuto social elevado, tanto del mismo rango como de categoría diferente» (2004, p. 615).

En el castellano medieval, el llamado voseo de cortesía acabó difundiéndose también en la población general, debido a los cambios sociales del final de la Edad Media y la entrada en el Renacimiento, llegando a su punto álgido a lo largo del siglo XV, pues comenzaron a emplearlo personas unidas por parentesco familiar o por alianzas matrimoniales, y no solo por conocidos y amigos. Si bien la escritura del Zifar es algo anterior a esto (principios del XIV), las posteriores ediciones pudieron ser testigo de los procesos de cambio. Sobre las formas de cortesía del tipo vuestra señoría, vuestra alteza o vuestra majestad, Eberenz afirma que son fruto de «la inflación de los usos voseantes en los siglos XV y XVI» (2004, p. 615): al verse incrementados en exceso los usos de nos y vos, la aparición de las nuevas formas de cortesía se explica como una necesidad del sistema formal. En el caso de vuestra merced, se puede comprobar en obras como la presente que ya desempeñaba esta función a lo largo del siglo XIV, aunque nunca fue predominante con respecto al voseo de cortesía fundamental. Sin embargo, según afirma De Granda (2007), el empleo de esta forma como diferenciadora de estatus entre locutor y receptor comenzó a darse a finales del XV.

En lo que respecta al Zifar, encontramos una abrumadora adición de esta forma a medida que avanzamos cronológicamente en las ediciones de la obra. De este modo, si en el manuscrito M la forma vos se encontraba en una cantidad 
destacable, en el manuscrito $\mathrm{S}$ se encuentra en la totalidad de secuencias estudiadas. He aquí algunos ejemplos que son prueba de ello:

15) a. Commo quisierdes dixo ella ( $\mathrm{M}, 26,25)$ / Commo vos quisierdes dixo ella (P y S, $26,25)$.

b. E non sabes dixo el ribaldo (M, 110, 10) / E non sabedes vos (P y S, 110, 10).

c. Señora enbiastesle nunca (M, 392, 10) / Enbiastes vos nunca (P y S, 392, 10).

\section{Conclusiones}

La situación del pronombre en época bajomedieval es, cuando menos, digna de análisis. El XV es uno de los siglos en los que se aglutinan más variaciones en la morfosintaxis pronominal, tan solo superado por los siglos de gestación del romance castellano. El paso de la época medieval al XVI entrañó cambios de cuantiosa importancia, no solo a nivel morfosintáctico, sino también fonético y léxico; aunque quizá la gramática sea la que más se vio alterada en este siglo.

A lo largo de este estudio se ha pretendido estudiar el paradigma pronominal personal bajo el enfoque de su situación concreta en los siglos XIV y XV, pero sin olvidar tampoco cuestiones contextuales de importancia para entender esos cambios morfológicos, como son las evoluciones fonéticas de los mismos. El análisis de los manuscritos ha permitido visualizar la situación de ciertos tipos de pronombre a lo largo de los tres siglos que comprenden las tres ediciones estudiadas. Si bien la mayoría de las variaciones encontradas muestran datos esperados acorde a la cronología de las ediciones, como son la pérdida de conbusco/conuusco en $\mathrm{S}$, la aparición de gelo en todas las ediciones, la progresiva omisión de la forma locutiva indefinida lo al en las ediciones $\mathrm{P}$ y $\mathrm{S}$ o el cambio de $v o s<o s$ en la edición sevillana; encontramos también otros cambios que no muestran de forma exacta la temporalidad de cada manuscrito: ejemplos de ello son el conservadurismo de $\mathrm{P}$, apreciable en la aparición sistemática de vos frente a os, siendo este manuscrito tan solo medio siglo anterior a $\mathrm{S}$, o los frecuentes casos de laísmo en $\mathrm{M}$, quizá algo tempranos para la cronología de este fenómeno (se documenta mayor número de casos a partir del XV). Se puede afirmar, por tanto, que el paradigma pronominal estudiado en los tres testimonios corresponde, en líneas generales, a la lengua de su tiempo. Sin embargo, existen excepciones o casos específicos (como los citados anteriormente) que no encajan del todo bien con la cronología relativa de los fenómenos. Las causas de ello pueden ser múltiples: ¿sería posible, por ejemplo, que la edición parisina sea más conservadora lingüísticamente por sus características codicológicas especiales? ¿Acaso la abundancia de casos de laísmo en M nos podría indicar que ya a mediados del XIV fuese frecuente este fenómeno en algunas zonas de la Península? Será necesario abordar el estudio de otros fenómenos lingüísticos que permitan contrastar los resultados parciales de este trabajo para poder responder de manera fundada a estas cuestiones. Lo que se puede afirmar con seguridad es que las variaciones entre las tres ediciones del Zifar ofrecen multitud de posibilidades para la investigación filológica, ya no solo en el ámbito pronominal, sino en cualquier otra parcela de la lengua. Se pretende, por tanto, continuar con el análisis de estas en trabajos futuros, con el fin de poder 
responder entonces a tantas cuestiones que quedan sin resolver, pero que servirán como punto de partida para un estudio de mayores dimensiones.

\section{Referencias}

\section{Fuentes primarias:}

1. Manuscrito $M=$ Ms. 11.309 de la Biblioteca Nacional de España en Madrid. Códice $M$. Siglo XIV.

2. Manuscrito $P=$ MS. espagnol 36 de la Biblioteca Nacional de Francia en París. Códice P. 1464

3. Manuscrito $S=$ Inv. Rés. $Y^{2} 259$ de la Biblioteca Nacional de Francia. Códice $S .1512$.

\section{Fuentes secundarias:}

1. Cacho Blecua, J. M. (1996). Los problemas del Zifar. En Rico, F. (Dir.). El Libro del Caballero Zifar. Códice de París. Barcelona: Moleiro.

2. Cacho Blecua, J. M. y Gómez Redondo, F. (2018). Proyecto Parnaseo. http://parnaseo2.uv.es/AulaMedieval/AulaMedieval.php?id=ContextosDelZifar [28/04/2021].

3. Cano Aguilar, R. (1988). El castellano medieval: morfosintaxis histórica. En El español a través de los tiempos. Madrid: Arco Libros.

4. De Andrés Castellanos, M. S. (1964). La vida de Santa María Egipciaca. Madrid: RAE.

5. De Granda, G. (2007). Hacia la diacronía de una forma de tratamiento en el español: su merced. Lexis: Revista de lingüística y literatura, 31 (1-2), pp. 165-175.

6. Eberenz, R. (2004). Cambios morfosintácticos en la baja Edad Media. En Cano Aguilar, R. (Coord.). Historia de la lengua española (pp. 613-642). Barcelona: Ariel.

7. Fernández-Ordóñez, I. (2006). Transmisión manuscrita y transformación "discursiva" de los textos. En Girón Alconchel, J. L. y Bustos Tovar, J. J. (Coords.) Actas del VI Congreso Internacional de Historia de la Lengua española (Vol. 2, pp. 1779-1808). Madrid: Arco Libros.

8. García, E. C. (1991). Variación sincrónica y equivalencia diacrónica: el caso de usco, CLHM, 16, pp. 5-51. https://doi.org/10.3406/cehm.1991.959

9. Girón Alconchel, J. L. (2004). Cambios gramaticales en los Siglos de Oro. En Cano Aguilar, R. (Coord.) Historia de la lengua española (pp. 859-93). Barcelona: Ariel.

10. Gomila-Albal, M. (2018). Variación diacrónica y diatópica de con + pronombre personal de $1^{\underline{a}}$ y $2^{\underline{a}}$ persona del plural. Bulletin of Hispanic studies, 95, pp. 801-823. https://doi.org/10.3828/bhs.2018.47

11. González, C. (1983). Libro del Caballero Zifar. Madrid: Cátedra.

12. Hammermüller, G. (2010). Evolución de las formas de tratamiento del español medieval hasta el siglo XVI. En Hummel, M., Kluge, B. y Vázquez Laslop, Ma E. (Aut.) Formas y fórmulas de tratamiento en el mundo hispánico (pp. 507-530). México: El Colegio de México.

13. Hernández Martínez, F. J. (1978). Ferrán Martínez, escrivano del Rey, canónigo de Toledo y autor del Libro del Cavallero Zifar. Revista de Archivos, bibliotecas y museos, 81 (2), pp. 289-325.

14. Lapesa Melgar, R. (2000). Estudios de morfosintaxis histórica del español. Edición de Cano Aguilar, R. y Echenique Elizondo, Mㅁ T. Madrid: Gredos.

15. Leal Abad, E. (2008). Configuraciones sintácticas y tradiciones textuales. Los diálogos medievales. Sevilla: Universidad de Sevilla.

16. Lucía Megías, J.M. (1996). Los Testimonios del Zifar. En Francisco Rico (Dir.) El Libro del Caballero Zifar. Códice de París. Barcelona: Moleiro.

17. Malkiel, Y. (1948). Hispanic Algu(i)en and related Formation; a Study of the Stratification of the Romance Lexicon in the Iberian Peninsula. Los Ángeles: Berkeley. 
18. Menéndez Pidal, R. (1973). Manual de gramática histórica española. Madrid: Espasa Calpe.

19. Moldenhauer, G. (1931). La fecha del origen de la Historia del Caballero Cifary su importancia para la historia de la literatura española. Investigación y progreso, 5, pp. 175-176.

20. Nebrija, A. de (1492). Gramática de la lengua castellana. Salamanca: Juan de Porras.

21. Octavio De Toledo, Á. S. (2011). Santa Teresa y la mano visible: sobre las variantes sintácticas del Camino de perfección. En Castillo Lluch, M. y Pons Rodríguez, L. (Coords.) Asi se van las lenguas variando: nuevas tendencias en la investigación del cambio lingüístico en español (pp. 241-304). Bern: Peter Lang.

22. Penny, R. (1993). Gramática histórica del español, Barcelona: Ariel.

23. Pons Rodríguez, L. (2006). Canon, edición de textos e historia de la lengua cuatrocentrista. En Pons Rodríguez, L. (coord) Historia de la lengua y crítica textual (pp. 69-126). Madrid/Frankfurt am Main: Iberoamericana/Vervuert. https://doi.org/10.31819/9783865278609-004

24. Real Academia Española y Asociación de Academias de la Lengua Española (2010). Nueva gramática de la lengua española. Madrid: Espasa Calpe.

25. Serradilla Castaño, A. (1997). El régimen de los verbos de entendimiento y lengua en español medieval. Madrid: Universidad Autónoma de Madrid.

26. Sicot-Domínguez, S. (2002). La filiación del se «espúreo». El paso de ge a se: ¿evolución o sustitución? En Echenique Elizondo, Ma - T. y Sánchez Méndez, J. (Eds.) Actas del V Congreso Internacional de Historia de la Lengua Española (Vol. 1, pp. 1021-1028). Madrid: Gredos.

27. Wagner, C. P. (1929). El Libro del Caballero Zifar. Michigan: Ann Arbor, University of Michigan. 